DR. ELINA REINOSO (Orcid ID : 0000-0001-7724-8379)

$$
\text { Article type : Original Article }
$$

\title{
Characterization of an Enterococcus faecium strain in a murine mastitis model
}

\section{D. Montironi ${ }^{1}$, M. V. Moliva ${ }^{1}$, N. A. Campra ${ }^{1}$, J. M. Raviolo ${ }^{2}$, G. Bagnis ${ }^{2}$, L. N. Cariddi $^{1}$} and E. B. Reinoso ${ }^{1 a^{*}}$

${ }^{1}$ Departamento de Microbiología e Inmunología, Facultad de Ciencias Exactas, Físico-Químicas y Naturales, Universidad Nacional de Rio Cuarto, Rio Cuarto X5804ZAB, Ruta 36 Km 601, Córdoba, República Argentina

${ }^{2}$ Facultad de Agronomía y Veterinaria, Universidad Nacional de Rio Cuarto, Rio Cuarto X5804ZAB, Ruta 36 Km 601, Córdoba, República Argentina

\section{Study of an Enterococcus faecium strain}

\section{Correspondence}

Elina Reinoso Departamento de Microbiología e Inmunología, Facultad de Ciencias Exactas, Físico-Químicas y Naturales, Universidad Nacional de Rio Cuarto, Rio Cuarto X5804ZAB, Ruta 36 Km 601, Córdoba, República Argentina.ereinoso@exa.unrc.edu.ar

This article has been accepted for publication and undergone full peer review but has not been through the copyediting, typesetting, pagination and proofreading process, which may lead to differences between this version and the Version of Record. Please cite this article as doi: $\underline{10.1111 / J A M .14554}$

This article is protected by copyright. All rights reserved 
Aim: To characterize phenotypically and genotypically Enterococcus faecium strains collected from bovine mastitis milk and to evaluate one of them for its virulence in a murine mastitis model. Methods and Results: Five E. faecium isolates were collected from cows with subclinical mastitis. EF-7A showed resistance to antibiotics tested, it presented alpha hemolysin and did not present gelatinase activity. It yielded $c y A$, efafm and gelE1 genes and it could be characterized as a moderate biofilm producer. It was able to internalize in MAC-T cells and $1 \times 10^{8}$ Colony Forming Unit $\mathrm{ml}^{-1}$ was able to establish an intramammary infection in mice. The strain could be recovered from liver, kidney and blood samples. RAPD profiles showed different bands respect to the inoculated strain. Histopathology analyses showed different grades of polymorphonuclear neutrophils infiltration in mammary glands.

Conclusion: This is the first report that studied E. faecium strain in a lactating mouse model of mastitis and showed that the experimental inoculation was able to stimulate an inflammatory response resulting in mastitis. Results contribute to a better understanding of intramammary infections caused by E. faecium.

Significance and Impact of the Study: This investigation shows that mice represent a valuable model for the study of the mastitis pathogenesis caused by E. faecium considering the high costs of using cows for mastitis research.

Keywords: Enterococcus faecium, mastitis, murine model, virulence 


\section{Introduction}

Bovine mastitis is a disease that produces significant economic losses to the dairy industry around the world (Hogeveen et al. 2011). Mastitis is caused by a wide variety of agents that affect milk quality and yield. Different efforts have been made to control the disease and vaccines have had little success because numerous agents are able to cause the disease. Control programs, as vaccines, should be able to decrease the frequency of new infections (Bradley et al. 2015).

Among Gram positive bacteria, streptococci and enterococci are important agents of intramammary infection in dairy herds, being the major pathogens responsible for high bulk tank somatic cell counts in appropriate managed herds (Carrillo-Casas and Miranda-Morales 2012). The primary source of environmental mastitis pathogens is the cow surroundings since infections usually take place during the milking practice.

Enterococcus spp. are part of the normal microbiota of gastrointestinal and urogenital systems of mammals. Due to their high tolerance to adverse conditions, they occupy a great variety of niches being part of the microbiota of the soil, natural waters and plants (Lebreton et al. 2014). Methods to control these agents sometimes are inadequate (Smith and Hogan 1993). Mastitis can be caused by both the contact of the teat with the enterococcal pathogen and the host immune resistance to infection (Smith and Hogan 2003). E. faecium and E. faecalis can cause bovine mastitis (Carrillo-Casas and Miranda-Morales 2012). E. faecium secretes several molecules that are putative virulence factors, including enterococcal surface protein gene (esp), aggregation substances (agg), cell wall adhesins (efaAfm), gelatinase ( $g e l E)$ and cytolysin (cyl) (Eaton and Gasson 2001). Different virulence factors have also been described in enterococci isolated from food of animal origin (Valenzuela et al. 2009). Furthermore, the capacity to form biofilm is also considered as a virulence factor for enterococcal infections contributing to antibiotic resistance (Eaton y Gasson 2002; Tendolkar et al. 2004). Additionally, the Enterococcus group is wellknown for its ability to transfer conjugative plasmids (Clewell 1990), increasing the virulence and leading to antibiotic resistance. This fact represents an important problem for therapeutic treatment.

To our knowledge, there is limited information available on E. faecium as mastitis agent (Petersson-Wolfe et al. 2009). Furthermore, different studies have been assayed using murine models. Among them, Sillanpää et al. (2010) reported a study of virulence in a murine model of urinary tract infection. Leendertse et al. (2009) studied the role of the enterococcal surface protein 
Esp in the ability to adhere to uroepithelial cells and the role that it plays in urinary tract infection and peritonitis by using Esp-expressing E. faecium (E1162) and its isogenic Esp-deficient mutant (E1162 $\Delta e s p)$ in a murine model. Similarly, Panesso et al. 2011 studied the $h y l_{E f m}$ gene, which has been considered as a virulence determinant of hospital-associated E. faecium. They constructed mutants of the $h y l_{E f m}$-region and they evaluated their effect on virulence using a murine peritonitis model. However, no study reports the use of a murine model for E. faecium as a mastitis pathogen. The development of experimental intramammary infection models facilitate the study of the mastitis pathogenesis.

The aim of this study was to characterize phenotypically and genotypically E. faecium strains collected from bovine mastitis milk and to evaluate one of them for its virulence in a murine mastitis model.

\section{Materials and methods}

\section{Bacterial isolates}

Twelve milk samples were collected from cows, with subclinical mastitis. Each milk sample was collected from an individual cow. Mastitis diagnosis was obtained from field veterinarians and subclinical disease was diagnosed based on SCC values that exceeded 250.000 cells $/ \mathrm{ml}^{-1}$ (Ruegg 2010). Milk samples were kept on ice until processing.

Bacterial isolates were identified as streptococci or enterococci according to conventional bacteriological methods (Texeira et al. 2012) by colony appearance, Gram stain reaction, and catalase test (Hogan et al. 1999) and later confirmed by 16 rRNA -sequencing and additionally by matrix assisted laser desorption/ionisation - time of flight mass spectrometry (MALDI-TOF MS system - Bruker Daltonik MALDI Biotyper). 16 rRNA -sequencing was carried out by CERELACONICET sequencing service and MALDI-TOF analysis by Microbiology Laboratory of the Hospital Privado Universitario de Córdoba service. Bacterial isolates were maintained frozen at $20^{\circ} \mathrm{C}$ in Todd-Hewitt broth (THB Sigma-Aldrich Co.) containing 20\% glycerol, for further characterization.

\section{Phenotypic characterization}


All bacterial isolates were subcultured from storage media onto THB for phenotypic characterization.

\section{Antibiotic susceptibility testing}

Antibiotic susceptibility was determined by the standardized agar diffusion test on Müller-Hinton agar ( $\mathrm{MH}$, Britania, Argentina) according to the recommendations of Clinical and Laboratory Standards Institute (CLSI 2013). The following antibiotic disks currently applied on mastitis treatment were used: ampicillin $\left(10 \mu \mathrm{g} \mathrm{ml}^{-1}\right)$, gentamicin $\left(10 \mu \mathrm{g} \mathrm{ml}^{-1}\right)$, streptomycin $\left(15 \mu \mathrm{g} \mathrm{ml}{ }^{-1}\right)$, chloramphenicol $\left(30 \mu \mathrm{g} \mathrm{ml} \mathrm{m}^{-1}\right)$, teicoplanin $\left(30 \mu \mathrm{g} \mathrm{ml} \mathrm{m}^{-1}\right)$, erythromycin $\left(15 \mu \mathrm{g} \mathrm{ml}^{-1}\right)$ and vancomycin $\left(30 \mu \mathrm{g} \mathrm{ml}^{-1}\right)$ (Britania, Argentina). Isolates were categorized as susceptible and resistant. E. faecalis ATCC 29212 was used as quality control.

\section{Enterococcal virulence factors}

Production of gelatinase and hemolysin was determined (Eaton and Gasson 2001). Gelatinase was assayed in tubes with $3 \mathrm{ml}^{-1}$ of Todd-Hewitt broth with the addition of gelatin (4\%). After $24 \mathrm{~h}$ of incubation at $37^{\circ} \mathrm{C}$, tubes were cooled for $35 \mathrm{~min}$ at $4^{\circ} \mathrm{C}$ and results were observed. Hemolysin production was determined on defibrinated horse blood agar plates. The isolates were grown during $24 \mathrm{~h}$ at $37^{\circ} \mathrm{C}$ and production of hemolysins was determined as clearer areas around bacterial colonies. Assays were repeated three times in different occasions.

\section{Biofilm assay}

The ability of E. faecium strains to form biofilm in vitro, on an abiotic surface, was determined using a sterile 96-well flat bottom polystyrene plate as described previously (Moliva et al. 2017). Briefly, bacteria were grown during $24 \mathrm{~h}$ in Trypticase Soy Broth (TSB, Britania, Argentina) supplemented with $0.25 \%$ of glucose on polystyrene microplates, wells were washed, stained with crystal violet and then washed three times. Ethanol was added to each well and optical density at $560 \mathrm{~nm}\left(\mathrm{OD}_{560}\right)$ was measured using an ELISA reader (Labsystems Multiskan MS). A previously characterized biofilm producing isolate, Staphylococcus epidermidis, was used as a positive control in biofilm assays (Moliva et al. 2017). TSB was used as negative control. Strains were 
categorized as strong, moderate and weak biofilm formers as reported by Moliva et al. 2017, utilizing a scale based on the average optical density of the blank wells plus three times the standard deviation of the mean.

\section{Adherence and internalization assay}

Adherence assays were carried out as described by Matthews et al. (1994) with modifications. MAC-T cells were grown in Dulbecco's modified Eagle's medium (DMEM, Gibco, Grand Island, NY) supplemented with addition of heat-inactivated fetal bovine serum (10\%, GIBCO), hydrocortisone $\left(4 \mu \mathrm{g} \mathrm{ml}^{-1}\right)$ and antibiotics (Antibiotic Mixture: ATM (100x), GIBCO). Prior to each assay, cells were diluted at $5 \times 10^{4}$ cells/well in 96-well culture plates and incubated during 24 $\mathrm{h}$ at $37^{\circ} \mathrm{C}$ in $5 \% \mathrm{CO}_{2}$ to $100 \%$ confluence growth. Cells were washed with PBS and co-cultured with bacterial inoculum at a multiplicity of infection (MOI, ratio of E. faecium to cells) of 10:1 for $2 \mathrm{~h}$ at $37^{\circ} \mathrm{C}$ in $5 \% \mathrm{CO}_{2}$. Cells were washed with PBS, lysed with Triton $0.025 \%$ and MAC-T lysates were diluted 10-fold. Then, they were plated on Tripticase Soy Agar (TSA, Britania, Argentina) and incubated overnight at $37^{\circ} \mathrm{C}$. Colony Forming Units per $\mathrm{mL}\left(\mathrm{CFU} \mathrm{m}{ }^{-1}\right)$ of the bacteria adhered to MAC-T cells were determined by standard colony counting technique.

An assay to determine the ability of the bacteria to internalize was performed. After incubation with bacteria, the cells were treated with gentamicin $\left(100 \mathrm{mg} \mathrm{ml}^{-1}\right)$ for $1 \mathrm{~h}$ to kill extracellular bacteria. Finally, MAC-T monolayers were washed, lysed again with Triton $0.025 \%$ and diluted 10-fold, plated on TSA and incubated overnight at $37^{\circ} \mathrm{C}$. CFU ml-1 of E. faecium internalized in MAC-T cells were determined

An Escherichia coli, non-invasive strain, was used as negative control for internalization assay ( $0 \%$ of invasion). Experiments were conducted in triplicate and repeated three times.

\section{Genotypic characterization}

\section{Amplification of virulence associated genes}

The presence of gelE, esp, agg, cylL and efaAfm genes were analyzed by PCR assays using oligonucleotide primers derived from the published sequences reported by Eaton and Gasson 2001. The oligonucleotides were synthesized by Promega Corporation. A negative control with 
water instead of chromosomal DNA was included in each run. In addition, a characterized chromosomal DNA (E. faecium ATCC 29212) was included as positive control for efa, cylA and efaAfm genes.

\section{Plasmid isolation}

Plasmid extraction was performed according to Al-Doori et al. (2001), using lysozyme (10 mg ml1) and $\mathrm{NaOH}(0.2 \mathrm{~N}) / \mathrm{SDS}(1 \%)$. Plasmids were visualized by electrophoresis in $0.8 \%$ agarose.

\section{Experimental animals}

Balb/c female lactating mice, aged 6-8-weeks, (weighing 18-20 g), supplied from Bioterio Central of the National University of Río Cuarto, were maintained in a temperature and humidity room controlled, with $12 \mathrm{~h}$ light-dark cycles and were allowed food and water ad libitum. All experimental procedures were conducted according to the Guide for the Care and Use of Laboratory Animals 2011 and approved by Ethics Committee of Scientific Research (CoEdI), Universidad Nacional de Río Cuarto under resolution 121/2015 CoEdI - UNRC.

An E. faecium strain was used for murine model assay. The strain was grown for $18 \mathrm{~h}$ on TSB and its optical density $\left(\mathrm{OD}_{660}\right)$ values were adjusted to the appropriate bacterial concentrations. Animals were injected by intramammary route at 10 and 15 days of lactation, according to the protocol described by Chandler (1970). Mice were separated into 10 groups (2 mice per group and per time) and were inoculated in the left and right fourth mammary glands (L4 and $\mathrm{R} 4$, respectively) as follows:

- Groups 1-5: received $100 \mu$ l of phosphate buffer saline pH 7.4 (PBS) (control groups).

-Groups 6-10: received $100 \mu \mathrm{l}$ of a suspension containing different concentrations of E. faecium EF-7A strain $\left(1 \times 10^{2}, 1 \times 10^{3}, 1 \times 10^{5}, 1 \times 10^{7}\right.$ and $\left.1 \times 10^{8} \mathrm{CFU} \mathrm{ml}^{-1}\right)$.

Prior to bacterial inoculation of the mammary glands, mice were separated from their pups according to Trigo et al. (2009), with modifications. Mice were anaesthetized with $87 \mathrm{mg} \mathrm{kg}^{-1} \mathrm{of}$ ketamine (Vetanarcol ${ }^{\circledR}$ König, Buenos Aires, Argentina) and $13 \mathrm{mg} \mathrm{kg}^{-1}$ of xylazine (Rompun ${ }^{\text {M.R. }}$ Bayer, Buenos Aires, Argentina) (Brouillette et al. 2004). The mothers were returned to the pups 8 $\mathrm{h}$ after the inoculations. 
After 24, 48, 72, 96 and $360 \mathrm{~h}$ (15 days) post-inoculation the mice were sacrificed by cervical dislocation and the mammary glands, kidneys, heart and liver were removed aseptically.

\section{Bacteria growth curve}

Five colonies of the E. faecium strain grown on blood agar at $37^{\circ} \mathrm{C}$ for $18 \mathrm{~h}$ were transferred to 5 $\mathrm{ml}$ of TSB. The pre-culture was incubated at $37^{\circ} \mathrm{C}$ with agitation for $16 \mathrm{~h}$. Then, $80 \mathrm{ml}$ of TSB was inoculated with $0.4 \mathrm{ml}$ of the pre-culture (dilution $1 / 200$ ) and incubated at $37^{\circ} \mathrm{C}$. Samples were taken from the culture every $2 \mathrm{~h}$, during a period of $10 \mathrm{~h}$. The number of total cells per $\mathrm{ml}$ was measured by $\mathrm{OD}_{660}$ and the number of viable cells per $\mathrm{ml} \mathrm{CFU} \mathrm{ml}^{-1}$ was determined. The assay was repeated in two independent experiences.

\section{Bacteriological examination}

Mammary glands, kidneys and liver were homogenized in $1 \mathrm{ml}$ of PBS. Ten-fold dilutions of the mammary gland homogenates were done and the number of $\mathrm{CFU} \mathrm{ml^{-1 }}$ was determined by plating logarithmic dilutions of the tissue samples on TSA by duplicate and incubated at $37^{\circ} \mathrm{C}$ for $24 \mathrm{~h}$. Plates were examined for bacterial growth and isolated colonies were identified according to standard procedures. Samples of kidneys and liver homogenates were cultured in TSA plates. Blood samples from heart were also cultured. E. faecium EF-7A colonies were identified according to standard procedures (Texeira et al. 2011).

\section{Random Amplified Polymorphic DNA (RAPD-PCR)}

RAPD-PCR assays were carried out according to Reinoso et al. (2004) in order to compare the genetic profiles of the strains recovered from the different organs with the inoculated strain. The oligonucleotide OLP13 (5'-ACCGCCTGCT-3) was used for DNA amplification. Negative and positive controls were included in each run. The assay was repeated three times in different occasions. RAPD-PCR products were separated by electrophoresis in a $1.5 \%$ agarose gel (Promega) in $0.5 \mathrm{X}$ TBE buffer at a constant voltage of $4 \mathrm{~V} / \mathrm{cm}^{-1}$ stained with GelGreen ${ }^{\mathrm{TM}}$ and photographed under UV light with MiniBisPRO gel documentation (BioAmerica, USA). A 100 bp 
DNA marker (Promega) was used as a DNA molecular size standard. DNA fingerprints of the isolates were compared for similarity by visual inspection of the band profiles.

\section{Histopathological analysis}

Samples of mammary glands were fixed in neutral buffer with $4 \%$ formaldehyde, paraffinembedded, and sections (5 $\mu$ m thick) were cut and stained with haematoxylin and eosin (H/E) or were Gram stained. Sections were examined by light microscopy Zeiss Axiostar plus and pictures were obtained using a Canon G5 Camera System. The evaluation of polymorphonuclear neutrophils (PMNs) infiltration in the tissue was performed by microscopic visualization in 10 randomly selected fields per slide and a score was assigned according to Boulanger et al. (2007). The score 0 represented no PMNs infiltration; 1 a weak PMNs infiltration; 2 a moderate one and 3 a strong one with severe changes. All slides were read in a blind trial, by a veterinary pathologist.

\section{Statistical analysis}

All the values obtained in the assays were expressed as averages with standard deviations. The data obtained were evaluated using GraphPad Prism version 5.00.288 (San Diego, USA, 2007), compared with one-way analysis of variance (ANOVA) and the Tukey multiple comparison test. Differences were considered statistically significant at $\mathrm{p}<0.05$.

\section{Results}

\section{Phenotypic and genotypic characterization}

In this study, bacterial isolates were identified as streptococci or enterococci. Five isolates were identified as enterococci. To obtain a bacterial identification, sequence analysis of the 16S rRNA genes were performed and examined by Chromas version 2.6.4. The five isolates were identified as E. faecium ( $\max$ score 971, total score 971, 88\% identity). Subsequently, the samples were analyzed by MALDI-TOF MS, which confirmed the isolates as E. faecium (value score of 2.324).

The five strains, named as EF-2, EF-3, EF-4, EF-5 and EF-7A were phenotypically and genotypically characterized. Antibiotic susceptibility testing showed that all the strains were 
resistant to streptomycin while no resistance to teicoplanin was observed. Only EF-7A strain showed resistance to six out of the seven antibiotics tested (ampicillin, gentamicin, streptomycin, chloramphenicol, erythromycin and vancomycin). Table 1 showed obtained results.

All the strains assayed produced hemolysin and gelatinase activity.

Biofilm assay showed that all strains were able to produce biofilm and could be characterized as moderate biofilm producers, according to the categorization reported by Moliva et al. (2017). Furthermore, E. faecium strains were investigated for various virulence associate genes. The five strains and E. faecium control strain yielded cylA and efaAfm genes. PCR amplification of gelE gene yielded an amplicon size of approximately 400 bp for EF-7A, EF-3, EF-4 strains and E. faecium control strain. On the other hand, agg and esp genes could not be amplified in any strain.

In addition, it was found that the five E. faecium strains carried plasmids (Fig. 1).

The ability to adhere and internalize in host cells of E. faecium strains was evaluated by the epithelial MAC-T cell invasion assay. It was observed that the strains had different levels of adhesion to MAC-T cells expressed as CFU ml-1. Our results showed different levels of invasion among strains. However, EF-7A strain showed a high adhesion capacity compared to the other strains. In addition, EF-7A strain showed ability to internalize in MAC-T cells. Differences in invasion capacity were observed between EF-7A and E. coli $(\mathrm{p}<0.05)$ (Fig. 2). No viable internalized E. coli was detected.

\section{Murine mastitis model}

According to phenotypic and genotypic results, EF-7A strain was selected for intramammary inoculation assays. The E. faecium EF-7A strain growth curve showed an initial phase of latency of $2 \mathrm{~h}$, followed by an exponential growth phase between 2 and $4 \mathrm{~h}$. The maximum cell growth was determined at $6 \mathrm{~h}$ with $1.2 \times 10^{9} \mathrm{CFU} \mathrm{ml}^{-1}$ (Fig. 3).

Mice were infected intramammary with several concentrations of E. faecium EF-7A, but only $1 \times 10^{8} \mathrm{CFU} \mathrm{ml}{ }^{-1}$ was able to establish an infection in mammary glands and no animal died. The mean viable counts decreased from $8.34 \log \mathrm{CFU} \mathrm{ml} l^{-1}$ at time 0 to $3.3 \log \mathrm{CFU} \mathrm{m} \mathrm{m}^{-1}$ at $360 \mathrm{~h}$ in mammary gland samples. Fig. 4 shows the logarithms of total numbers of CFU recovered from mammary glands, inoculated with $1 \times 10^{8} \mathrm{CFU} \mathrm{ml}^{-1}$, over the time. Although, bacterial counts were sharply decreasing until $48 \mathrm{~h}(\mathrm{p}<0,001$ respect to initial inoculum). A slight increase in the 
bacterial load was observed at $72 \mathrm{~h}$. A slow decrease was followed up to $360 \mathrm{~h}$ (15 days) and no clearance of bacteria was observed during the assay.

EF-7A strain could be isolated from liver and kidney homogenates of inoculated mice at 24, 48, 72 and $96 \mathrm{~h}$ post-inoculation. Bacterial counts were $2 \times 10^{3} \mathrm{CFU} \mathrm{ml}^{-1}$ in kidneys and $1 \times 10^{4}$ CFU ml-1 in liver at $24 \mathrm{~h}$. Nevertheless, bacterial counts decreased one log at $48 \mathrm{~h}$ and could be recovered at $72 \mathrm{~h}$ and $96 \mathrm{~h}$. In addition, EF-7A strain could also be cultured from blood samples at different times $(24,48,72,96 \mathrm{~h})$. No bacteria could be recovered from negative control.

Bacteria recovered from liver and kidneys were identified as E. faecium according to standard procedures. Furthermore, RAPD-PCR assays were performed in order to compare the genetic profile of the inoculated strain with bacteria recovered from liver and kidneys. The primer used in this study was able to amplify several polymorphic DNA fragments from all samples and reproducible RAPD band profiles were generated. Fig. 5 presents the RAPD profiles obtained. The genetic profiles of the recovered strains at different times $(24,48,72,96 \mathrm{~h}, 15$ days) showed some different bands with respect to the inoculated strain (line 2). However, all the strains (inoculated strain as recovered strains) shared most of the RAPD bands. Furthermore, identical profiles were obtained within each time.

No macroscopic alteration in the mammary gland inoculated with PBS (control group) along the different times assayed were observed. On the other hand, mammary glands of the inoculated group showed both discoloration and increase in their weight compared with the control group.

Histopathology changes were evaluated microscopically with H/E staining. Figures 6 and 7 show microphotographs of histopathological analyses and the score of PMNs infiltration in mammary glands of female Balb/c lactating mice inoculated with $1 \times 10^{8} \mathrm{CFU} \mathrm{ml}^{-1}$ of E. faecium EF-7A, respectively. Histopathology analyses showed that tissue structures were intact in the control group. Likewise, satisfactory milk secretion was observed. On the other hand, mammary glands of the inoculated group showed a moderate PMNs infiltration at $24 \mathrm{~h}$ without loss of glandular architecture tissue. A strong PMNs infiltration and loss of alveolar integrity was observed at 48 h. Finally, a moderate to strong PMNs infiltration was observed at 72 and 96 h, together with a thickening of the walls of the alveoli and a strong hyperemia. It is important to note that PMNs infiltration occurred in the inoculated group at $96 \mathrm{~h}$ simultaneously with the presence of macrophages and lymphocytes. In addition, histopathological analysis at 15 days showed a weak infiltration. Furthermore, a gradual increase of adipocytes was observed in control 
groups and in groups which received EF-7A $1 \times 10^{8} \mathrm{CFU} \mathrm{m}{ }^{-1}$. However, the inoculated group with E. faecium strain showed a higher increase of adipocytes (Fig. 7).

Gram positive cocci could be visualized in the mammary tissue of the inoculated groups by Gram staining. A considerable number of bacteria in the lumen of alveoli, mammary interstitium or phagocytosed by PMNs as well as associated with or internalized by the mammary cells were observed (Fig. 8).

\section{Discussion}

Five E. faecium strains were pheno and genotypically characterized. The strains had different antibiotic resistance patterns and EF-7A showed multiple antibiotic resistance included vancomycin. Similarly, Wu et al. (2006) reported that pathogenic enterococci isolated from mastitic cows were frequently resistant to penicillin and sporadically to ampicillin and vancomycin. Different reports on Enterococcus spp. susceptibilities to antibiotics were reported in the literature. Nam et al. (2010) did not find any enterococci resistant to vancomycin, but Kuyucuoğlu (2011) found that $4.3 \%$ of the strains were resistant. Detection of vancomycin resistance is important due to the ability to transfer resistance. It has been known that enterococci group exchanges both antibiotic resistance and virulence genes among members of their genus and of other genera as well as Gram negative and Gram positive bacteria. These gene transfer mechanisms are efficient and important due to association with antibiotic resistance (Mundi et al. 2000; Herráez 2008). So, detection of vancomycin resistance in enterococci collected from mastitic milk needs special attention.

E. faecium has been reported of being capable to produce biofilm. In this study, biofilm assay showed that E. faecium strains could be characterized as moderate biofilm producers. Soares et al. (2014) studied 19 E. faecium strains and reported that two isolates were able to form biofilm, but they were considered weak adherents. The importance of biofilm formation is that biofilm is considered a virulence factor and contributes to antibiotic resistance (Eaton and Gasson 2001).

Different virulence factors contribute to mammary gland infection. Gelatinase encoded by gelE is involved in biofilm formation and hydrolyzes collagen, casein, and hemoglobin (Shankar et al. 1999; Hancock and Perego 2004). Break down of proteins could be important for invasion and dissemination in the mammary gland. gelE gene could be detected in E. faecium EF-7A, EF-3 and EF-4 strains and they were able to produce this enzyme in vitro. This result is in contrast with 
those of other reports which indicated that the occurrence of gelE gene is not necessarily associated with gelatinase activity (Marra et al. 2007; Comerlato et al. 2013).

The five E. faecium strains yielded cylA gene and efaAfm gene. cylA encodes a cytolysin that can cause damage to cell membranes, enabling infection. Otherwise, efaAfm gene is involved in the adhesion of the bacteria to biotic and abiotic surfaces favoring biofilm formation (PérezPulido et al. 2006). The five E. faecium strains yielded efaAfm gene and were able to produce biofilm in vitro. In addition, efaAfm gene has been showed to be involved in evasion of the immune response (Pérez-Pulido et al. 2006) and to have a crucial role in infective endocarditis caused by Enterococcus (Mohamed et al. 2004). The presence of cylA and efaAfm genes in E. faecium strains may improve colonization ability and their high resistance to different antibiotics could lead to increase virulence.

The E. faecium strains, assayed in this work, were able to adhere and internalize MAC-T cells. Similar results were reported in E. faecalis (Elhadidy and Zarhan 2013). Adhesion and internalization to the mammary epithelium are important facts for the development of the infection (Opdebeeck et al. 1988). However, according to our data, adhesion level and percentage of internalization did not seem to be related to each other.

According to the results obtained, E. faecium EF-7A strain was selected to evaluate its virulence in a murine mastitis model. The strain showed a typical growth curve, with a decrease in the cell values after $8 \mathrm{~h}$ due to a possible lysis effect.

Mice were infected by intramammary route with several concentrations of E. faecium EF$7 \mathrm{~A}$, but only $1 \times 10^{8} \mathrm{CFU} \mathrm{ml} \mathrm{m}^{-1}$ was able to establish an infection in mammary glands. The bacteria could be recovered from mammary glands over the time. Silvestrini et al. (2007) reported that the number of Staphylococcus aureus strain Newbould 305 (ATCC 29740) recovered from the mammary gland increased at $24 \mathrm{~h}$ post-inoculation and a strong decrease in the bacterial load was reported at $48 \mathrm{~h}$, followed by a slight increase at $72 \mathrm{~h}$ post-inoculation. Rowson et al. (2010) and Forsberg et al. (2012) developed a murine mastitis model of Streptococcus uberis using CD-1 mice and reported that the pathogen was able to colonize the mammary gland after the intramammary inoculation with $50 \mathrm{CFU} \mathrm{ml}^{-1}$ at $48 \mathrm{~h}$ post-infection. Similarly, Zhao et al. (2015) using a $S$. aureus strain isolated from goats, informed that the strain was not completely removed from the mammary gland. These results agree partly with those observed in this study suggesting that E. faecium EF-7A, as other mastitis agents, may persist on mammary gland after intramammary inoculation. 
In addition, EF-7A strain could be isolated from liver and kidney homogenates of inoculated mice at different times assayed post-inoculation. This result revealed that EF-7A strain could diffuse from the mammary gland and had the capacity to invade other organs as liver and kidney. Brouillette et al. (2004) reported that S. aureus Newbould 305 (ATCC 29740) was able to disseminate from mammary glands to kidneys after $12 \mathrm{~h}$ post-intramammary inoculation of different bacterial concentrations. Even though the study was carried out with S. aureus strains, the results agree with those obtained in the present study, where E. faecium EF-7A strain was recovered from kidneys after intramammary inoculation. On the other hand, Trigo et al. (2009) inoculating $1 \times 10^{8} \mathrm{CFU} \mathrm{ml}^{-1}$ of a Streptococcus agalactiae using Balb/c mice observed an increase in the bacterial load recovered from kidneys and liver at 12 and $24 \mathrm{~h}$ post-inoculation, respectively.

Different molecular methods, as RAPD-PCR, REP-PCR and PFGE have been applied to evaluate the genetic diversity of mastitis pathogens. In this work, RAPD-PCR was chosen because it is a rapid, simple, easy, and less expensive technique applicable to any genome. The primer used was previously employed for RAPD typing of $S$. aureus mastitis bacterial strains (Reinoso et al. 2004). The presence of different RAPD profiles, according to the time of isolation, suggests that genetic changes of the strain may occur in vivo during the infection. To our knowledge, no reports about genotypic characterization of bacteria recovered from the mammary gland of mice inoculated with E. faecium strains are described. Khazandi et al. (2015) working with S. uberis on a cow mastitis challenge infection model, showed that the RAPD profiles of the recovered strains were identical to RAPD profiles of the inoculated strain. Similarly, Quesnell et al. (2012) reported that the RAPD profile of an E. coli strain inoculated by intramammary route did not change its genetic profile at least 48 to $96 \mathrm{~h}$ post-challenge. These results contrast with those obtained in our study, since RAPD profiles of the recovered strains presented different bands along the time assayed (24, 48, 72, 96 and $360 \mathrm{~h}$ post-inoculation). According to the presence of plasmids in the strains assayed, our results may be related with the fact that Enterococcus genera is characterized by its high capacity to acquire external genetic material by conjugation or by transference of plasmids or transposons in vivo (Johnston and Jaykus 2004; Albornoz 2005).

Data obtained in the present study agree with different works which reported that the inoculation of a pathogenic strain in a mouse mastitis model caused mastitis symptoms. Furthermore, the histology of inoculated mammary glands can be compared with bovine mammary glands infected (Akers and Nickerson 2011). Results of the histopathology analysis 
agreed with the bacterial growth in the mammary gland inoculated with E. faecium EF-7A $1 \times 10^{8}$ UFC $\mathrm{ml}^{-1}$. The intensity of the inflammation observed in the mammary glands of inoculated groups may be due to the presence of a constant number of bacteria from $48 \mathrm{~h}$ to 15 days. In addition, the presence of the bacteria in the mammary gland during all times assayed, showed that E. faecium EF-7A could not be removed by effector cells of the innate immune system, as PMNs and macrophages. This fact induced the activation of the defense mechanisms of adaptive immunity evidenced by the presence of lymphocytes in the mammary tissue at $96 \mathrm{~h}$ after infection. Our results agree with Rowson et al. (2010) who observed a massive infiltration of PMNs together with a loss of breast tissue integrity $48 \mathrm{~h}$ after $50 \mathrm{CFU} \mathrm{ml}{ }^{-1}$ of $S$. uberis inoculation.

The dissimilarities found in the different studies could be attributed to the pathogen studied, its virulence factors and the number of bacteria inoculated as well. It is important to note that the experimental infection degree of the environmental pathogens such as streptococci and enterococci is considered highly variable and lower than contagious pathogens such as staphylococci. Furthermore, mice strains used may be slightly susceptible to infection by streptococci (Chandler 1970).

This is the first report that studied E. faecium strain in a lactating mouse model of mastitis. Results showed the capacity of E. faecium EF-7A strain to produce intramammary infection in mice. This investigation shows that mice represent a valuable model for the study of the mastitis pathogenesis caused by E. faecium considering the high costs of using cows for mastitis research.

\section{Acknowledgments}

This work was supported by grants from and PICT 2268/13. Mic. I.D. Montironi, M.V. Moliva and N.A. Campra have Fellowship from CONICET. Dr. E.B. Reinoso and Dr. L.N. Cariddi are Members of the Research Career of CONICET. The authors thanks to Prof. Susana Vilor de Perotti for correction of the manuscript.

\section{Conflict of Interest}

The authors have no conflict of interest to declare.

\section{References}


Akers, R.M. and Nickerson, S.C. (2011) Mastitis and its impact on structure and function in the ruminant mammary gland. J Mammary Gland Biol Neoplasia 16, 275-289.

Albornoz, H., Bangulo, H., Camou, T., Guerra, S. and Scarppita, C. (2005) Guías de prevención y control de enterococcos resistente a vancomicina. Ministerio de Salud Pública.

Al-Doori, Z., Hill, R.L.R., Casewell, M.W. (2001). Use of a "Miniprep” for rapied extraction of plasmids for vancomycin- and gentamicin-resistant Enterococcus faecium. World J Microb Biot 17, 517-521.

Boulanger, D., Brouillette, E., Jaspar, E., Malouin, F., Mainil, J., Bureau, F. and Lekeux, P. (2007) Helenalin reduces Staphylococcus aureus infection in vitro and in vivo. Vet. Microbiol 119, 330-338.

Bradley, A.J., Breen, J.E., Payne, B., White, V. and Green, M.J. (2015) An investigation of the efficacy of a polyvalent mastitis vaccine using different vaccination regimens under field conditions in the United Kingdom. J Dairy Sci 98, 1706-1720.

Brouillette, E., Grondin, G., Lefebvre, C., Talbot, B.G. and Malouin, F. (2004) Mouse mastitis model of infection for antimicrobial compound efficacy studies against intracellular and extracellular forms of Staphylococcus aureus. Vet Microbiol 101, 253-262.

Carrillo-Casas, E.R. and Miranda-Morales, R.E. Bovine Mastitis Pathogens: Prevalence and Effects on Somatic Cell Count; in N. INTECH Open science, Management and Health (eds) Chaiyabutr, Milk Production, An Up-to-Date Overview of Animal Nutrition. Open minds doi: 10.5772/1525. ISBN 978-953-51-0765-1 pp 359-374.

Chandler, R.L. (1970) Experimental bacterial mastitis in the mouse. J Med Microbiol 3, 273-282.

Clewell, D.B. (1990) Movable genetic elements and antibiotic resistance in enterococci Eur J Clin Microbiol Infect Dis 9, 90-102.

Comerlato, C.B., Resende, M.C., Caierão, J. and d'Azevedo, P.A. (2013) Presence of virulence factors in Enterococcus faecalis and Enterococcus faecium susceptible and resistant to vancomycin, Memorias do Instituto Oswaldo Cruz 108, 590-595 doi.org/10.1016/j.foodcont.2008.06.004.

CLSI - Clinical Laboratory Standards Institute. Performance standards for antimicrobial susceptibility testing. Document M100-S23. Twenty-third Informational Supplement. Wayne, PA, USA: CLSI; 2013. 
Eaton, T.J. and Gasson, M.J. (2001) Molecular screening of Enterococcus virulence determinants and potential for genetic exchange between food and medical isolates. Appl Environ Microbiol 67, 1628-1635 doi: 10.1128/AEM.67.4.1628-1635.

Elhadidy, M. and Zahran, E. (2013) Biofilm mediates Enterococcus faecalis adhesion, invasion and survival into bovine mammary epithelial cells. Lett Appl Microbiol 58, 248-254.

Forsberg, N.E., Wang, Y.Q., Corbett, R.B., James, D. and Chapman, J.D. (2012) Neutrophil $\begin{array}{llll}\text { Killing } & \text { Efficacy } & \text { of }\end{array}$ http://phibromarketing.s3.amazonaws.com/_documents/201506/2eda551659ac10b30537e94 ae5d3de7f.pdf.

Hancock, L.E. and Perego, M. (2004) The Enterococcus faecalis $f_{s r}$ two-component system controls biofilm development through production of gelatinase. J Bacteriol 186, 5629-5639. doi: 10.1128/JB.186.17.5629-5639.

Herráez, C. (2008) Lactococcus lactis productores de pediocina pa-1 y enterococos aislados de leche materna como agentes bioconservantes en quesos $\mathrm{PhD}$ thesis, Universidad Complutense de Madrid, Madrid

Hogeveen, H., Huijps, K. and Lam, T.J. (2011) Economic aspects of mastitis: new developments. N Z Vet J 59, 16-23. doi:10.1080/00480169547165.

ILAR. (2011) Guide for the Care and Use of Laboratory Animals. In The National Academies Press. Washington, DC.

Johnston, L. and Jaykus, L. (2004) Antomicrobial resistence of Enterococcus species isolated from produce. Appl Environ Microbiol 70, 3133-3137.

Khazandi, M., Eats, P., Trott, D., Ebrahimie, E., Perry, J., Hickey, E., Page, S., Garg, S. and Petrovski, K.R. (2015) Development of an improved Streptococcus uberis experimental mastitis challenge model using different doses and strains in lactating dairy cows. $J$ Dairy Res 82, 470-477. doi: 10.1017/S0022029915000321.

Kuyucuoğlu, Y. (2011) Antibiotic resistances of enterococci isolated from bovine subclinical mastitis. Eurasian J Vet Sci 27, 231-234.

Lebreton, F., Willems, R.J.L., and Gilmore, M.S. (2014) Enterococcus Diversity, Origins in Nature, and Gut Colonization. In Enterococci: From Commensals to Leading Causes of Drug Resistant Infection [Internet] ed. Gilmore, M.S., Clewell, D.B., Ike, Y., Shankar, N. pp. 1-59. Boston: Massachusetts Eye and Ear Infirmary. 
Leendertse, M., Heikens, E., Wijnands, L.M., van Luit-Asbroek, M., Teske, G.J.D., Roelofs, J.J.T.H., Bonten, M.J.M., van der Poll, T., Willems, R.J.L. (2009) Enterococcal Surface Protein Transiently Aggravates Enterococcus faecium-Induced Urinary Tract Infection in Mice. J Infect Diseases 200, 1162-1165. doi.org/10.1086/605609.

Marra, A., Dib-Hajj, F., Lamb, L., Kaczmarek, F., Shang, W., Beckius, G., Milici, A. J., Medina, I. and Gootz, T.D. (2007) Enterococcal virulence determinants may be involved in resistance to clinical therapy. Diagn Microbiol Infect Dis 58, 59-65. doi: 10.1016/j.diagmicrobio.2006.11.024.

Matthews, K.R., Almeida, R.A. and Oliver, S.P. (1994) Bovine mammary epithelial cell invasion by Streptococcus uberis. Infect Immun 62, 5641-5646.

Mohamed, J.A., Huang, W., Nallapareddy, S.R., Teng, F. and Murray, B.E. (2004) Influence of origin of isolates, especially endocarditis isolates, and various genes on biofilm formation by Enterococcus faecalis. Infect Immun 72, 3658-3663.

Moliva, M.V., Cerioli, E.B. and Reinoso, E.B. (2017) Evaluation of environmental and nutritional factors and sua gene on in vitro biofilm formation of Streptococcus uberis isolates. Microb Pathog 107, 144-148. doi: 10.1016/j.micpath.2017.03.028.

Mundy, L.M., Sahm, D.F. and Gilmore, M. (2000) Relationships between enterococcal virulence and antimicrobial resistance. Clin Microbiol Rev 13, 513-522.

Nam, H.M., Lim, S.K., Moon, J.S., Kang, H.M., Kim, J.M., Jang, K.C., Kim, J.M., Kang, M.I., Joo, Y.S. and Jung, S.C. (2010) Antimicrobial resistance of enterococci isolated from mastitic bovine milk samples in Korea. Zoonoses Public Health 57, 59-64.

Opdebeeck, J.P., Frost, A.J. and O'Boyle, D. (1988) Adhesion of Staphylococcus aureus and Escherichia coli to bovine udder epithelial cells. Vet Mic 16, 77-86.

Panesso, D., Montealegre, M.C., Rincón, S., Mojica, M.F., Rice, L.B., Singh, K.V., Murray, B.E. and Arias, C.A. (2011). The hyl Efm gene in pHylEfm of Enterococcus faecium is not required in pathogenesis of murine peritonitis. BMC Microbiol 11, 20 (2011). doi: 10.1186/1471-2180-11-20.

Pérez-Pulido, R., Abriouel, H., Omar, N.B., Lucas, R., Martinez-Canamero, M. and Galvez, A. (2006) Safety and potential risks of Enterococci isolated from traditional fermented capers. Food Chem Toxicol 44, 2070-2077. 
Petersson-Wolfe, C.S., Wolf, S.L. and Hogan, J.S. (2009) Experimental challenge of bovine mammary glands with Enterococcus faecium during early and late lactation. J Dairy Sci $\mathbf{9 2 ,}$ 3158-3164. doi: 10.3168/jds 2008-1755

Quesnell, R.R., Klaessig, S., Watts, J.L. and Schukken, H. (2012) Bovine intramammary Escherichia coli challenge infections in late gestation demonstrate a dominant antiinflammatory immunological response. J Dairy Sci 95, 117-126. doi: 10.3168/jds.20114289.

Reinoso, E., Bettera, S., Frigerio, C., Di Renzo, M., Calzolari, A. and Bogni, C. (2004) RAPDPCR analysis of Staphylococcus aureus strains isolated from bovine and human hosts. Microbiol Res 159, 245-255. doi: 10.1016/j.micres.2004.002.

Rowson, A.D., Wang, Y.Q., Aalseth, E., Forsberg, N.E. and Puntenney, S.B. (2010) Effects of an immunomodulatory feed additive on the development of mastitis in a mouse infection model using four bovine-origin isolates. Animal 5, 220-229 doi: 10.1017/S1751731110001850.

Ruegg, P.L. (2010) Test used to Diagnose Mastitis on Dairy Farms. APROCAL - Asociación Pro Calidad de leche y sus derivados. http://www.aprocal.com.ar/categoria/mastitis/

Shankar, V., Baghdayan, A.S., Huycke, M.M., Lindahl, G. and Gilmore, M.S. (1999) Infectionderived Enterococcus faecalis strains are enriched in esp, a gene encoding a novel surface protein. Infect Immun 67, 193-200.

Sillanpää, J., Nallapareddy, S.R., Singh, K.V., Prakash, V.P., Fothergill, T., Ton-That, H. and Murray, B.E. (2010) Characterization of the ebpfm pilus-encoding operon of Enterococcus faecium and its role in biofilm formation and virulence in a murine model of urinary tract infection. Virulence 1, 236-246.

Silvestrini, P., Beccaria, C., Pereyra, E.A.L., Renna, M.S., Ortega, H.H., Calvinho, L.F., Dallard, B.E. and Baravalle, C. (2007) Intramammary inoculation of Panax ginseng plays an immunoprotective role in Staphylococcus aureus infection in a murine model. Res Vet Sci 115, 211-220. doi: 10.1016/j.rvsc.2017.05.010.

Smith, K.L. and Hogan, J.S. (1993) Environmental mastitis. Vet Clin North Am Food Anim Pract 9, 489-498.

Smith, K.L. and Hogan, J.S. (2003) Environmental mastitis caused by species of Streptococcus and Enterococcus: risk factors and control, Ohio Agricultural Research and Development Center, The Ohio State University Wooster, USA. 
Soares, R.O., Fedi, A.C., Reiter, K.C., Caierão, J. and d'Azevedo, P.A. (2014) Correlation between biofilm formation and gelE, esp, and agg genes in Enterococcus spp clinical isolates. Virulence 5, 634-637. doi:10.4161/viru.28998.

Teixeira, L.M., Carvalho, M.G.S., Shewmaker, P.L., Facklam, R.R. (2011) Manual of clinical microbiology. American Society for Microbiology. Washington DC.

Tendolkar, P.M., Baghdayan, A.S., Gilmore, M.S. y Shankar. N. (2004). Enterococcal surface protein, Esp, enhances biofilm formation by Enterococcus faecalis. Infect Inmun 72, 60326039.

Trigo, G., Dinis, M., França, A., Bonifácio Andrade, E., Gil da Costa, R.M., Ferreira, P. and Tavares, D. (2009) Leukocyte populations and cytokine expression in the mammary gland in a mouse model of Streptococcus agalactiae mastitis. J Med Microbiol 58, 951-958. doi: 10.1099/jmm.0.007385-0.

Valenzuela, A.S., Omar, N.B., Abriouel, H., López, R.L., Veljovic, K., Cañamero, M.M., Ljubisa, Topisirovic, M.K.L., and Gálvez, A. (2009) Virulence factors, antibiotic resistance, and bacteriocins in enterococci from artisan foods of animal origin. Food Control 20, 381-385.

Wu, X., Hou, S., Zhang, Q., Ma, Y., Zhang, Y., Kan, W. and Zhao, X. (2006) Prevalence of virulence and resistance to antibiotics in pathogenic enterococci isolated from mastitic cows. J Vet Med Sci 78, 1663-1668. doi: 10.1292/jvms.15-0718.

Zhao, Y., Zhou, M., Gao, Y., Liu, H., Yang, W., Yue, J. and Chen, D. (2015) Helper Cell Polarization in a Murine Staphylococcus aureus Mastitis Model. PLoS ONE 10, e0134797 doi: 10.1371/journal.pone.0134797, eCollection.

Table 1. Susceptibility of Enterococcus faecium antimicrobials isolated from bovine subclinical mastitis.

\section{ISOLATE Antibiotic susceptibility testing}

AMP CHL ERY GEN STR TEC VAN

\begin{tabular}{lllllllll}
\hline EF-7A & R & R & R & R & R & S & R
\end{tabular}

\begin{tabular}{llllllll} 
EF-2 & S & R & R & S & R & S & S \\
EF-3 & S & S & I & R & R & S & S \\
EF-4 & S & S & R & S & R & S & S \\
EF-5 & S & S & R & S & R & S & S \\
\hline
\end{tabular}

This article is protected by copyright. All rights reserved 
References: Enterococcus faecium strains named as EF-7A, EF-2, EF-3, EF-4 and EF-5.

$\mathrm{R}$ : resistant S: sensitive

AMP: ampicillin, CHL: chloramphenicol, ERY: erythromycin, GEN: gentamicin, STR: streptomycin, TEC: teicoplanin, VAN: vancomycin. 


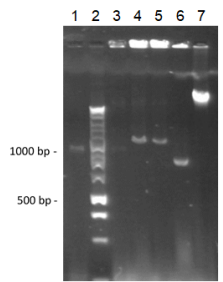

jam_14554_f1.tiff

Figure 1 Plasmid isolation of Enterococcus faecium strains isolated from bovine subclinical mastitis in $0.8 \%$ agarose gel. Lane 1: EF-2. Lane 2: 1 kb DNA marker, lanes 3 to 6: EF-3, EF-4, EF-5 and EF-7A strains. Lane 7: chromosomal DNA. 


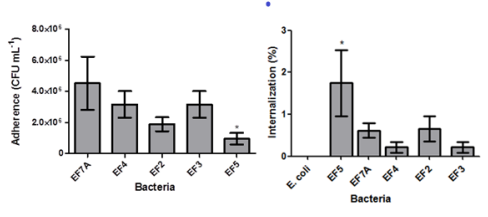

jam_14554_f2.tiff

Figure 2 Adhesion to and internalization into MAC-T cell of Enterococcus faecium strains isolated from bovine subclinical mastitis (EF-7A, EF-2, EF-3, EF-4 and EF-5). The bars represent the mean \pm the standard deviation of the mean (SEM). The mean corresponds to a triplicate of three independent trials. Asterisks indicate statistically significant differences $(p<0.05)$. 

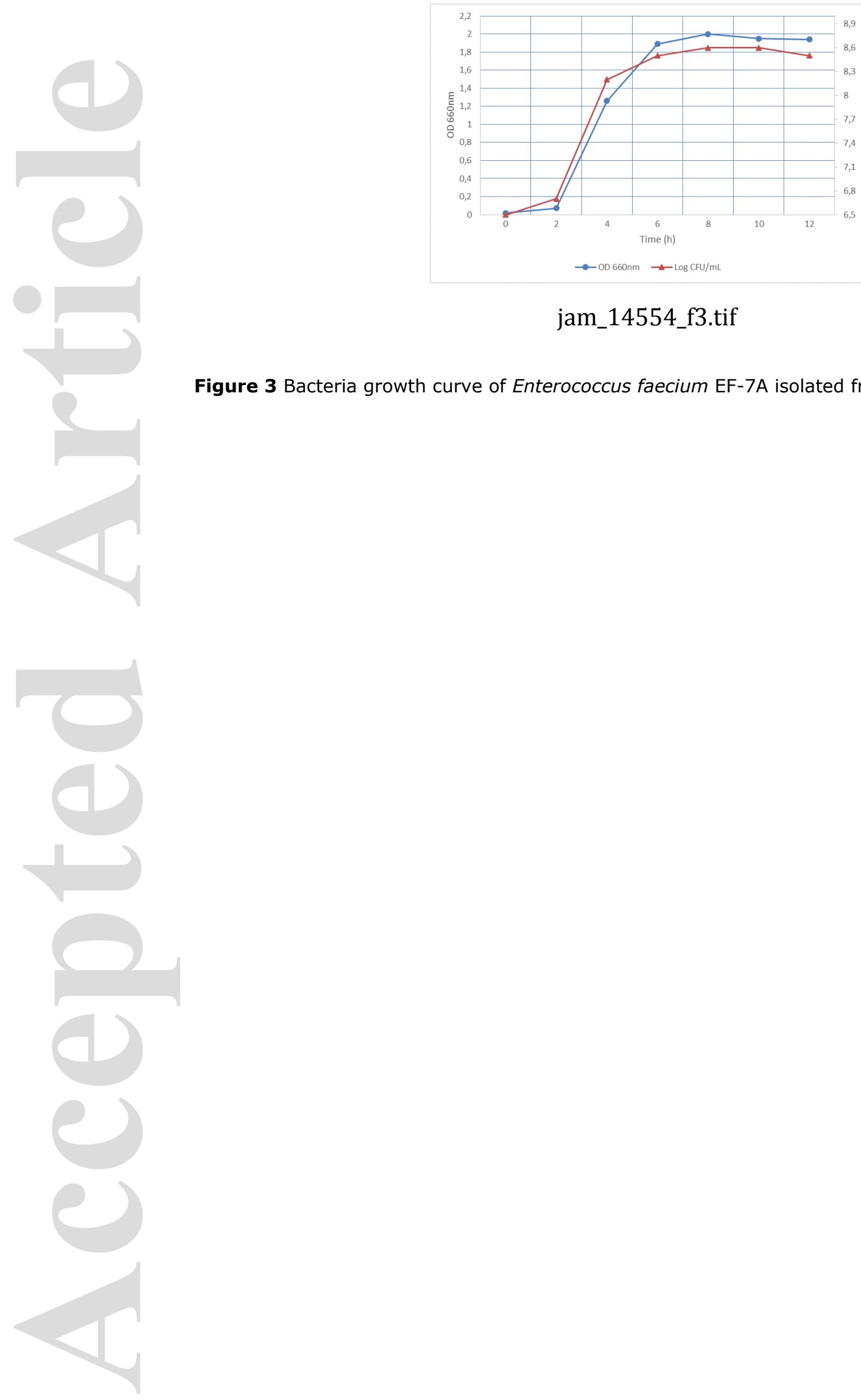

jam_14554_f3.tif

Figure 3 Bacteria growth curve of Enterococcus faecium EF-7A isolated from bovine subclinical mastitis. 


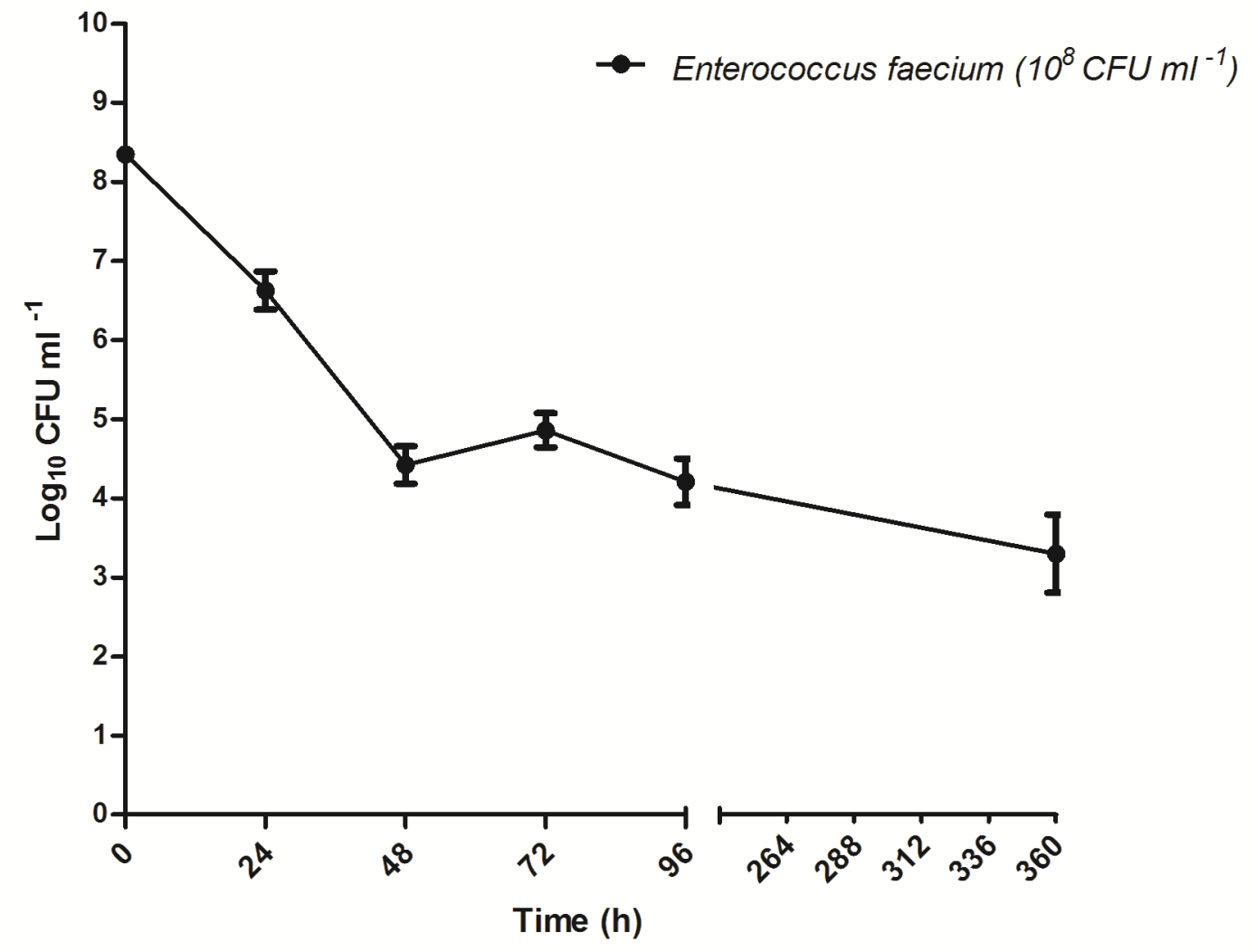

jam_14554_f4.tif

Figure 4 Number of bacteria (CFU $\mathrm{ml}^{-1}$ ) recovered from mammary glands of female lactating Balb/c mice inoculated with $1 \times 10^{8} \mathrm{CFU} \mathrm{ml^{-1 }}$ of Enterococcus faecium EF-7A strain isolated from bovine subclinical mastitis per mammary gland. Each value represents mean \pm SE of two mice (four mammary glands) per time point. 


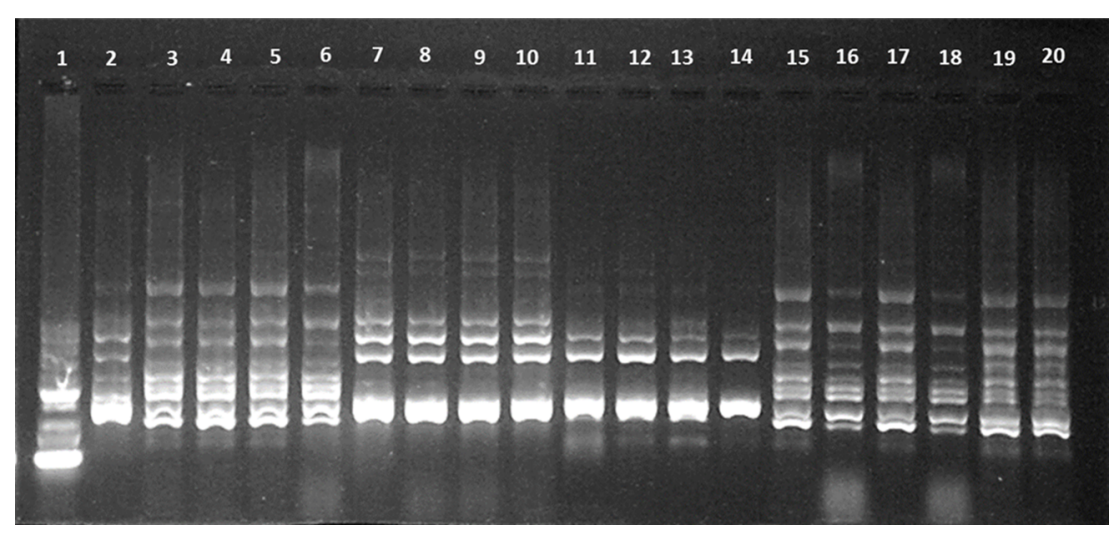

jam_14554_f5.tif

Figure 5 RAPD-PCR products in 1.5\% agarose gel recovered from mammary gland (MG) and different organs of mice inoculated with Enterococcus faecium EF-7A strain isolated from bovine subclinical mastitis. Line 1: Molecular weight marker of $100 \mathrm{bp}$. Line 2: inoculated strain EF-7A. Lines 3 to 6: strains recovered from R4 MG a, L4 MG b, liver and kidneys at $24 \mathrm{~h}$ post-inoculation, respectively. Lines 7 to 10 : strains recovered from R4 MG, L4 MG, liver and kidneys at $48 \mathrm{~h}$ post-inoculation, respectively. Lines 11 to 14 : strains recovered from R4 MG, L4 MG, liver and kidneys at $72 \mathrm{~h}$ post-inoculation, respectively. Lines 15 to 18: strains recovered from R4 MG, L4 MG, liver and kidneys at $96 \mathrm{~h}$ post-inoculation, respectively. Lines 19 and 20: strains recovered from R4 MG, L4 MG, at 15 days post-inoculation, respectively. aR4 MG: fourth right abdominal mammary gland. bL4 MG: fourth left abdominal mammary gland. 


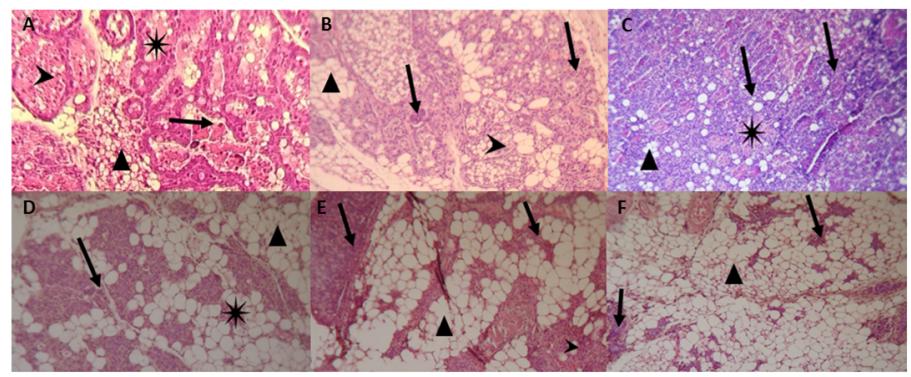

jam_14554_f6.tif

Figure 6 Histopathology of mammary glands of female lactating Balb/c mice. A) Inoculated groups with PBS (Control groups) at $96 \mathrm{~h}$ post-inoculation and B), C), D), E) and F) Inoculated groups with Enterococcus faecium EF-7A $1 \times 10^{8} \mathrm{CFU} \mathrm{ml}^{-1}$ at: $24 \mathrm{~h}, 48 \mathrm{~h}, 72 \mathrm{~h}, 96 \mathrm{~h}$ and $360 \mathrm{~h}$ post-inoculation, respectively. Arrows indicate the presence of PMNs, stars indicate lacteal secretion, arrowheads indicate alveoli and triangle indicate adipocytes. A gradual increase of adipocytes was observed in control groups and group inoculated with Enterococcus faecium EF-7A $1 \times 10^{8} \mathrm{CFU} \mathrm{ml}{ }^{-1}$. A higher increased was observed in group inoculated with the bacteria. Haematoxylin-eosin (H/E) stain. Magnification 10X. 


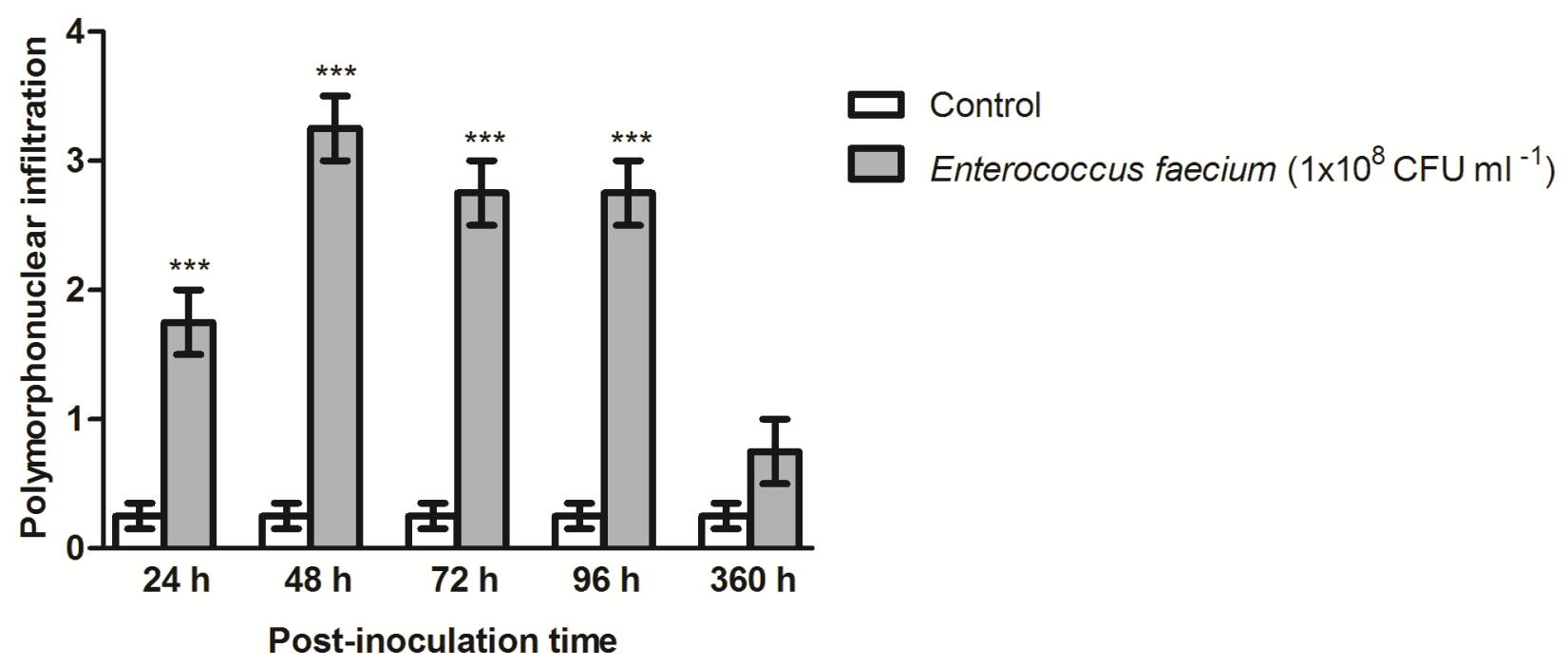

jam_14554_f7.tif

Figure 7 PMNs infiltration in mammary glands of female lactating Balb/c mice, inoculated with Enterococcus

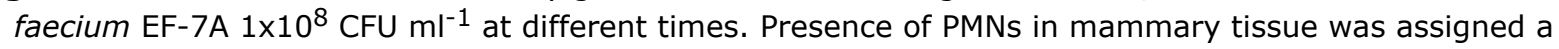
score. 0: no PMNs infiltration, 1: weak PMNs infiltration, 2: moderate PMNs infiltration 3: strong PMNs infiltration with severe changes. $* * * \mathrm{p}<0.001$ significant statistical difference compared to the infiltration observed in the mammary glands inoculated with PBS (control group). 


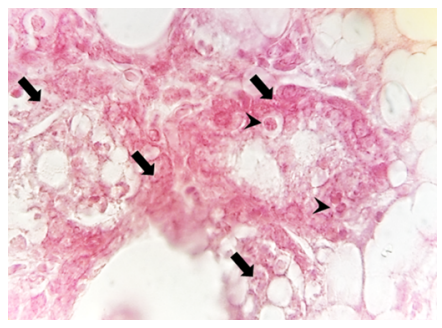

jam_14554_f8.tif

Figure 8 Gram stain section of mammary glands of female lactating Balb/c mice inoculated with Enterococcus faecium EF-7A strain $1 \times 10^{8} \mathrm{CFU} \mathrm{ml}-1$. Arrows indicate the presence of Gram positive cocci in the lumen of alveoli. Arrowhead indicates Gram positive cocci inside PMN. Magnification 100X. 